\title{
Editorial
}

\section{Jurgen Schulte}

\section{SciMERIT}

School of Mathematical and Physical Sciences

P.O. Box 123, Broadway NSW 2007

E-Mail: Jurgen.Schulte@uts.edu.au

DOI: http://doi.org/10.5130/pamr.v4i0.1463
PAM Review

Subject 68412 www.uts.edu.au

This is our fourth issue of PAM Review, the peer-reviewed student research journal of the School of Mathematical and Physical Sciences at the University of Technology Sydney. The student journal was first introduced into the third semester course Energy Science and Technology (68412) in 2014 to allow for a practical student centered, authentic learning experience that is exciting and challenging and helps to facilitate desired graduate attributes. Energy Science and Technology is a one-semester course (class) open to students in science as well as engineering that covers the thermodynamics of macroscopic and microscopic processes in the context of energy production and efficiency.

The compilation of this research journal provides students with an authentic, practical learning experience in applying scientific methods to produce a meta-study, peer-reviewed original research paper that reaches beyond a mere literature review. Each student self-selected research project is expected to contribute new knowledge to the body of science and engineering. The research task has been designed to create an environment similar to the creation of a real

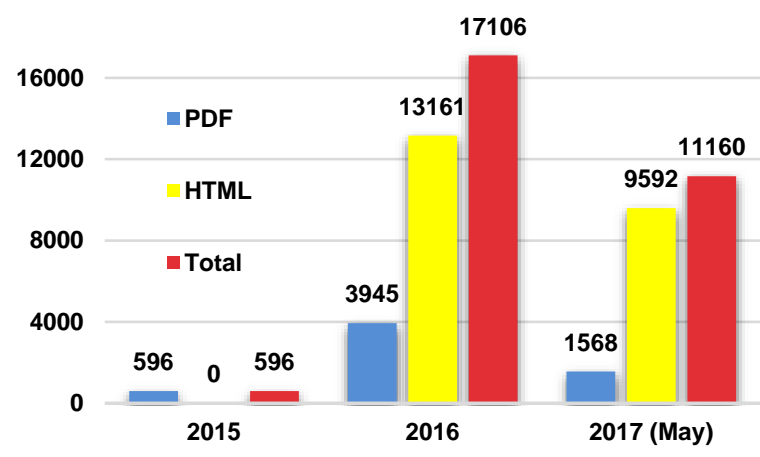

Unique article online views and document downloads. scientific research and publication process, including: gaining expertise in a range of scientific fields of science previously not encountered in the course; consulting professional scientific databases; studying peer-reviewed scientific papers; synthesizing relevant information; formulating a meta-study research objective; writing a scientific paper for a professionally published indexed journal; working in a research team with a range of expertise; peer-reviewing other research papers; completing the metastudy paper and its submission process within the journal's publication timeline.

The journal moved to the ePRESS peer-reviewed, open access publishing format in 2015. This made the students' research accessible to a much lager audience. Today, the students' work is read in over 60 countries. Within two years, open access PAM Review attracted a stellar number of readers worldwide, now well over 10,000 readers each year. It has been a rewarding experience for students to see that their research work attracted a truly worldwide interest and that the outcome of their work is now producing an impact well beyond their graduation. 